\title{
De novo sequencing and transcriptome analysis of the desert shrub, Ammopiptanthus mongolicus, during cold acclimation using Illumina/Solexa
}

Tao Pang, Chu-Yu Ye, Xinli Xia and Weilun Yin ${ }^{*}$

\begin{abstract}
Background: Ammopiptanthus mongolicus (Maxim. ex Kom.) Cheng f., an evergreen broadleaf legume shrub, is distributed in Mid-Asia where the temperature can be as low as $-30^{\circ} \mathrm{C}$ during the winter. Although A. mongolicus is an ideal model to study the plant response to cold stress, insufficient genomic resources for this species are available in public databases. To identify genes involved in cold acclimation (a phenomenon experienced by plants after low temperature stress), a high-throughput sequencing technology was applied.

Results: We sequenced cold-treated and control (untreated) samples of A. mongolicus, and obtained 65,075,656 and 67,287,120 high quality reads, respectively. After de novo assembly and quantitative assessment, 82795 allunigenes were finally generated with an average length of $816 \mathrm{bp}$. We then obtained functional annotations by aligning all-unigenes with public protein databases including NR, SwissProt, KEGG and COG. Differentially expressed genes (DEGs) were investigated using the RPKM method. Overall, 9309 up-regulated genes and 23419 downregulated genes were identified. To increase our understanding of these DEGs, we performed GO enrichment and metabolic pathway enrichment analyses. Based on these results, a series of candidate genes involved in cold responsive pathways were selected and discussed. Moreover, we analyzed transcription factors, and found 720 of them are differentially expressed. Finally, 20 of the candidate genes that were up-regulated and known to be associated with cold stress were examined using qRT-PCR.

Conclusions: In this study, we identified a large set of cDNA unigenes from A. mongolicus. This is the first transcriptome sequencing of this non-model species under cold-acclimation using Illumina/Solexa, a nextgeneration sequencing technology. We sequenced cold-treated and control (untreated) samples of $A$. mongolicus and obtained large numbers of unigenes annotated to public databases. Studies of differentially expressed genes involved in cold-related metabolic pathways and transcription factors facilitate the discovery of cold-resistance genes.
\end{abstract}

Keywords: Ammopiptanthus mongolicus, Cold acclimation, Transcriptome, Illumina/Solexa

\section{Background}

Ammopiptanthus mongolicus (Maxim. ex Kom.) Cheng $\mathrm{f}$. is an endangered angiosperm genus (Leguminosae) mainly distributed in the deserts of eastern central Asia [1]. As the only evergreen broad-leaved shrub in this area, it is particularly important for the ecologicalenvironmental stability of native habitats [2]. Moreover, the increasing desertification in central Asia is gradually

\footnotetext{
*Correspondence: xiaxl@bjfu.edu.cn; yinwl@bjfu.edu.cn

College of Biological Science and Biotechnology, National Engineering

Laboratory for Tree Breeding, Key Laboratory for Silviculture and

Conservation, Beijing Forestry University, Beijing 100083, China
}

becoming more serious in recent years [3]. Due to the important role that $A$. mongolicus plays in fixing moving sands and delaying further desertification, the protection and research on A. mongolicus are becoming particularly important and necessary [4]. Former studies on $A$. mongolicus have shown its capacity of resisting high solar radiation, heat, cold, and drought stresses $[5,6]$. Some genes involved in drought, cold, heat, and salinity tolerance have been identified, such as $A m C B L 1$ [7], AmLEA [8] AmVP1 [9], AmNHX2 [10] and AmCIP [11]. However, these studies on $A$. mongolicus are still limited and genomic resources of A. mongolicus (749 EST and 
155 nucleotide sequences in GeneBank prior to 11 January 2013) are also scarce. The ability to survive at $-30^{\circ} \mathrm{C}$ or lower temperatures makes A. mongolicus an ideal model for studying mechanisms of cold tolerance in plants. Therefore deeper understanding on genes expression profile of $A$. mongolicus under cold stress would be significative and imperative.

Cold acclimation; i.e., enhancement of the freezing tolerance of plants after low temperature stress, has been observed in many plants, including Arabidopsis [12], Oryza sativa [13], Triticum aestivum [14], and A. mongolicus [15]. During this process, plants alter the expression of certain genes as well as the biosynthesis of amino acids and soluble sugars. To elucidate the mechanism underlying cold acclimation, it is important to determine how plants alter gene expression in response to this biological process [16].

Compared with the traditional Sanger method, which is expensive and time consuming, next-generation sequencing (NGS) technologies or massively parallel sequencing technologies (e.g. Illumina/Solexa-based RNA-Seq technology) are much simpler and more cost-effective [17]. Furthermore, these high-throughput RNA sequencing (RNA-Seq) technologies have other advantages, such as accuracy and sensitivity for both low- and high-level gene expression [18], and facilitate rapid identification and analysis of the vast majority of transcriptomes [19]. Three main commercially available next-generation sequencing technologies are extant; namely, ABI/SOLiD, 454/Roche and Illumina/Solexa [20]. Illumina/ Solexa has been successfully applied to transcriptome sequencing of many plant species, including Populus euphratica [21], Aegilops variabilis [22] , Brassica napus [23], Zea mays [24], Arachis hypogaea [25], and Picrorhiza kurrooa [26].

Here, we describe the first transcriptome sequencing of A. mongolicus under cold-acclimation conditions using a next-generation sequencing technology, Illumina/Solexa. We sequenced two cDNA libraries (cold-treated and control samples) of living A. mongolicus tissues, and got an unprecedented amount of data. All sequences were deposited in Short Read Archive (SRA) division of the GenBank repository (accession no. SRA064010). Genes identified in this study expanded the available EST resources of $A$. mongolicus. Moreover, the analyses on differentially expressed genes under cold stress also furthers our understanding of the cold response mechanism of $A$. mongolicus, and the cold-related genes would also contribute to provide a method of developing cold-tolerant plants through genetic manipulation.

\section{Results}

Genome-size estimates

We determined the genome size of $A$. mongolicus by flow cytometry using cotyledons nuclei with maize $(\approx 2500 \mathrm{Mb}$ [27]) as an internal standard. The result showed that the genome size of $A$. mongolicus $(2 \mathrm{n}=18)$ was approximately $819.56 \pm 7.61 \mathrm{Mb}$ (Table 1 ), which was similar to that of another legume, the chick pea (Cicer arietinuum, $\approx 738 \mathrm{Mb}$ ) [28]. This is the first report of the genome size of $A$. mongolicus as far as we know. It is helpful to determine the sequencing depth.

\section{Illumina sequencing and reads assembly}

The two libraries (cold-treated and control samples), were sequenced respectively using Illumina $\mathrm{HiSeq}^{\mathrm{TM}}$ 2000. The total clean nucleotides generated from each sample exceeded $5.8 \mathrm{~Gb}$, that is, an unprecedented depth of seven times ( 7 -fold or $7 \times$ coverage) as much as the genome size $(819.56 \pm 7.61 \mathrm{Mb})$. We obtained approximately 71 million raw reads for the cold-treated sample (CT) and 73 million for the control sample (CK). We discarded low-quality reads, which contained adapters and unknown or low-quality bases, according to our bioinformatics analysis. A total of 65 million and 67 million clean reads were obtained from CT and CK samples, respectively. Of these clean reads, the total length was $11.9 \times 10^{9} \mathrm{nt}$ and the Q20 percentage (percentage of sequences with sequencing error rate lower than 1\%) was over $97 \%$ for both samples. All clean reads were also deposited in the National Center for Biotechnology Information (NCBI) and can be accessed in the Short Read Archive (SRA) under the accession number SRA064010.

Transcriptome de novo assembly was performed using Trinity, a short reads assembling program [29], which generated 145,000 (CT) and 148,797 contigs (CK) (Table 2). In both samples, the average contig size exceeded $300 \mathrm{nt}$, with the N50 of $500 \mathrm{nt}$. The contigs of each sample were then connected into unigenes, generating 76000 (CT) and 84583 unigenes (CK), respectively. After long-sequence clustering between both samples, 82795 all-unigenes were obtained. The sequencing coverage ranged from 1 - to 66245-fold (average, 45fold). The total length was $67,554,337 \mathrm{nt}$, with a mean length of 816 nt and an N50 of 1343 nt (i.e., 50\% of the assembled bases were incorporated into unigenes of 1343 nt or longer). Each all-unigene was longer than 200

Table 1 Flow cytometry determination of the nuclear genome sizes of $A$. mongolicus

\begin{tabular}{cccc}
\hline $\begin{array}{c}\text { A. mongolicus } \\
\text { peak }\end{array}$ & $\begin{array}{c}\text { Reference } \\
\text { peak }^{1}\end{array}$ & $\begin{array}{c}\text { Peak ratio } \\
\text { (Ammopiptanthus } \\
\text { /reference) }\end{array}$ & $\begin{array}{c}\text { A. mongolicus } \\
\text { genome size } \\
\text { (1C, Mb, Istandad } \\
\text { deviation) }\end{array}$ \\
\hline 15.53 & 47.07 & 0.329934141 & 824.8353516 \\
16.48 & 50.06 & 0.329204954 & 823.0123851 \\
15.62 & 48.16 & 0.324335548 & 810.8388704 \\
& & & $819.56 \pm 7.61$ \\
\hline
\end{tabular}

${ }^{1}$ Nuclei from maize young leaves serve as a size standard, which has a haploid genome size of $2500 \mathrm{Mb}$. 
Table 2 Overview of the sequencing and assembly

\begin{tabular}{llll}
\hline & Cold-treated & Control & Total \\
\hline Total Raw Reads & $71,441,910$ & $73,279,028$ & \\
Total Clean Reads & $65,075,656$ & $67,287,120$ & \\
Total Clean Nucleotides (nt) & $5,856,809,040$ & $6,055,840,800$ & \\
Q20 percentage & $97.39 \%$ & $97.60 \%$ & \\
N percentage & $0.00 \%$ & $0.00 \%$ & \\
GC percentage & $45.87 \%$ & $45.40 \%$ & \\
Contig & & & \\
Total Number & 145,000 & 148,797 & \\
Total Length(nt) & $45,723,903$ & $51,308,749$ & \\
Mean Length(nt) & 315 & 345 & \\
N50 & 521 & 619 & \\
Unigene & & & 82,795 \\
Total Number & 76,000 & 84,583 & $67,554,337$ \\
Total Length(nt) & $48,956,203$ & $57,108,594$ & \\
Mean Length(nt) & 644 & 675 & 816 \\
N50 & 1122 & 1191 & 40,985 \\
Total Consensus Sequences & 76,000 & 84,583 & \\
Distinct Clusters & 1,831 & 2,043 & 82,540 \\
Distinct Singletons & 74,169 & & \\
\hline
\end{tabular}

nt, and 35350 (42.70\%) unigenes were 200 to $400 \mathrm{nt}$. Also, 8066 (9.74\%) unigenes were longer than $2000 \mathrm{nt}$. The size distribution of the contigs and unigenes is shown in Figure 1.

\section{Functional annotation and classification}

We next performed BLAST (E-value $<0.00001$ ) analysis of the 82795 all-unigenes against protein databases, following a priority order of $\mathrm{Nr}$ (non-redundant protein sequences in NCBI), Swiss-Prot, KEGG (Kyoto Encyclopedia of Genes and Genomes database), and COG. There were 53398 (64.5\%) unigenes with homologous sequences in at least one of the above databases. Among them, 53252 (64.3\%), 30890 (37.3\%), and 27479 (33.2\%) unigenes were found in NR, SwissProt, and KEGG, respectively. A total of 22101 (26.7\%) unigenes were found in all three databases, while 29397 (35.5\%) unigenes were not identified (Figure 2).

We analyzed the 100 most-abundant transcripts of each sample and found some differences in functional annotations. Compared with control sample, the most-abundant transcripts in the cold-treated sample were dehydrin, the LEA protein precursor, SRC1 protein, defensin D1, early light inducible protein, SOS2-like protein kinase, Ethyleneresponsive transcription factor, and sucrose synthase. The 100 most-abundant transcripts are listed in Additional file 1.

We also identified a total of 1322 unigenes genes expressed only in the cold-treated sample. Functional annotations showed that some of them were closely related to cold stress, including calcium-transporting ATPase, serine/threonine-protein kinase, CBL-interacting protein kinase, late embryogenesis abundant protein, and dehydrin. Unigenes expressed only in the cold-treated sample are listed in Additional file 2.

Based on $\mathrm{Nr}$ annotations, we used the Gene Ontology (GO) classification system to classify the possible functions of the unigenes. A total of 23167 (28.0\%) unigenes were successfully assigned to at least one GO term annotation (Figure 3). The unigenes were then classified into three main categories: biological processes, cellular components, and molecular function. The category of biological processes consisted of 944 GO terms, which were assigned to 14719 (17.8\%) unigenes. The cellular components category consisted of 196 GO terms, which were assigned to 14095 (17.0\%) unigenes. The category of molecular functions consisted of 577 GO terms, which were assigned to 18775 (22.7\%) unigenes. For biological process, the top five largest categories were: "metabolic process" (9731), "cellular process" (8907), "response to stimulus" (3037), "biological regulation" (2502), and "localization" (2226). For cellular components, the top three largest categories were: "cell" (13821), "cell part" (12354), and "organelle" (9472). For molecular function, the top three largest categories were: "binding" (10876), "catalytic activity" (10452), and "transporter activity" (1215).

To assess the integrality of our transcriptome library and effectiveness of the annotation process, we aligned the all-unigenes to the COG database and 17327 (20.9\%) were identified. By classifying the possible functions of these unigenes, they were grouped into 25 functional categories (Figure 4). The largest category was "General function prediction only" (5504 of 17327 unigenes, about $31.8 \%$ ), followed by "Transcription" (3344 unigenes, about 19.3\%), "Replication, recombination and repair" (3248, 18.7\%), "Post-translational modification, protein turnover, chaperones" (2408, 13.9\%), and "Signal transduction mechanisms" (2402, 13.9\%). The categories of "Extracellular structures" (8, 0.046\%), "Nuclear structure" (20, 0.12\%) and "Cell motility" (257, 1.48\%) had the fewest responding genes. Also, 1576 (9.10\%) unigenes were annotated as "Function unknown".

We performed BLAST analysis of the 82795 allunigenes against the KEGG database to further analyze gene products during metabolic processes and determine their functions in cellular processes. A total of 27479 (33.2\%) unigenes matched 255,974 members, which were involved in 125 KEGG pathways. Of the 27479 unigenes, 5905 (21.49\%) were related to metabolic pathways, 2821 (10.27\%) were related to the biosynthesis of secondary metabolites, 1667 (6.07\%) to plant hormone signal transduction, 1060 (3.86\%) to RNA transport, and 975 $(3.55 \%)$ to the spliceosome. 


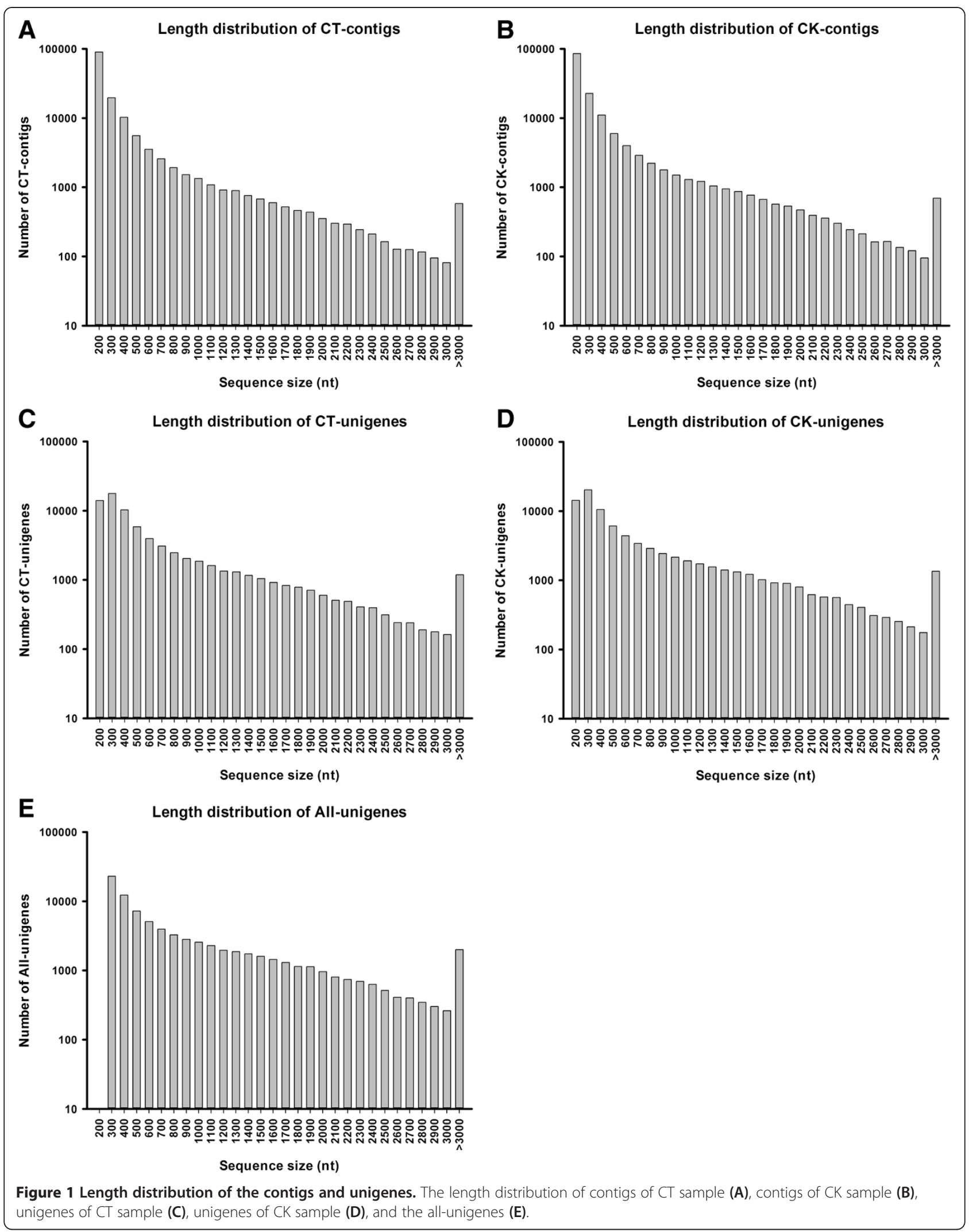




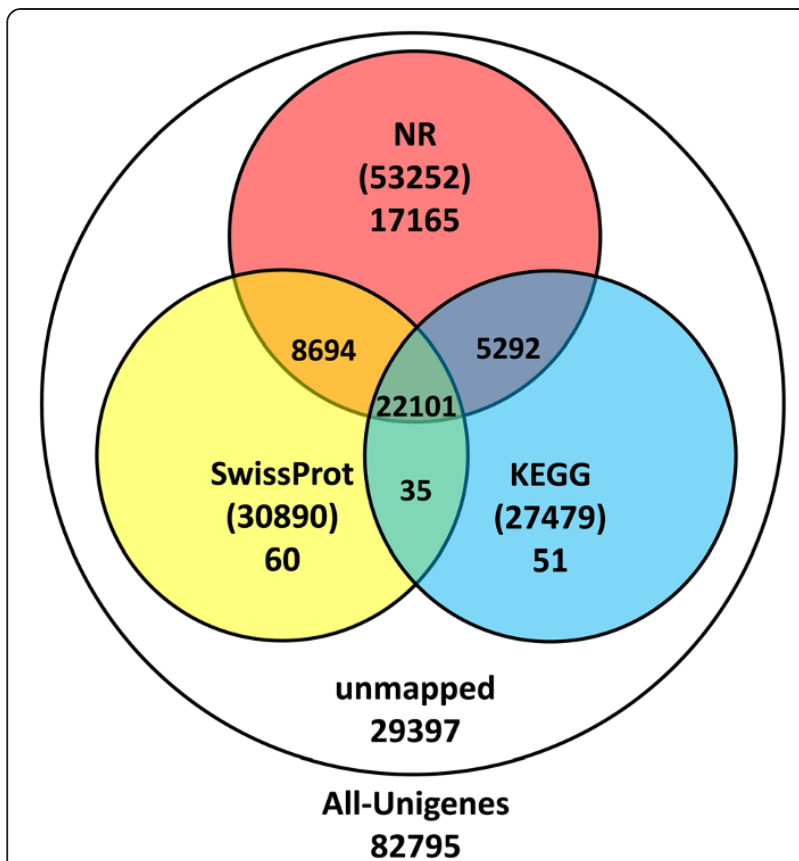

Figure 2 Number of unigenes blasted to NR, Swiss-Prot, KEGG and COG $(E<0.00001)$.

\section{Protein-coding region prediction}

After searching all-unigene sequences against protein databases using BLASTx (E-value $<0.00001)$ in the order mentioned in the functional annotation and classification section, we extracted 53485 coding sequences (CDS) from unigene sequences and translated them into peptide sequences. For unigenes with no BLAST hits, we used ESTScan to predict the 1936 CDS and translated them into peptide sequences. The distribution of the CDS is shown in Figure 5.

\section{Differential expression analysis}

To identify genes with different expression levels, we used the RPKM method (Reads Per kb per Million reads) to calculate the expression levels of the unigenes. The result showed that 9309 genes were up-regulated and 23419 genes were down-regulated with FDR $\leq 0.001$ and ratios larger than 2 . The distribution of transcript changes is shown in Figure 6.

We then mapped all differentially expressed genes to each term of the Gene Ontology database (http://www. geneontology.org/, release data: Aug 1st, 2012) and calculated the gene numbers from each GO term. Using a hypergeometric test, we identified significantly enriched GO terms in DEGs compared to the genomic background. GO terms with a corrected $p$ value $\leq 0.05$ were defined as significantly enriched in DEGs. The GO enrichment analysis results are shown in Additional file 3.

We also performed metabolic pathways enrichment analysis, and identified the primary biochemical pathways and signal transduction pathways in which DEGs involved. A total of 3868 up-regulated unigenes and 11691 down-regulated unigenes were identified to be involved in cold stress, on which all following analyses and discussions of metabolic pathway were based. These genes were related to 44 metabolic pathways, showing significantly changed under cold stress $(p \leq$ 0.05) including genes involved in carbohydrate, amino acid metabolism, energy, lipid, confactors and vitamins, terpenoids and polyketides, immune system, and environmental adaptation (Table 3).

\section{Transcription factor prediction}

A total of 1636 unigenes were identified to be involved in transcription, including 720 DEGs (209 up-regulated and 511 down-regulated) (Figure 7). The largest gene family was the ethylene-responsive element binding factor family (ERF), followed by the basic helix-loop-helix family (bHLH), C2H2 family, the Homeodomain-leucine zipper family (HD-ZIP), and the WRKY family.

\section{Quantitative real-time reverse transcription-PCR (qRT-PCR) analysis}

Our genome-wide expression analysis results were confirmed by quantitative real-time (qRT) PCR using TaqMan probes. We selected 20 unigenes, all of which are known to be related to cold stress, such as CBF (Crepeat-binding factors), LEA (Late embryogenesis abundant), LTI (low-temperature-induced), COR (cold-responsive), ERD (early dehydration-inducible), and DREB (dehydration-responsive element binding) [30,31]. The $\mathrm{Ct}$ values of $18 \mathrm{~S}$ rRNA of all samples ranged from 24.0 to 26.0. All 20 transcripts showed the same expression pattern as the in silico differential analysis results from high-throughput sequencing (Table 4).

\section{Discussion}

Ammopiptanthus mongolicus, the sole broad-leaved evergreen angiosperm genus in the deserts of eastern central Asia [32], can maintain its growth at temperatures as low as $-30^{\circ} \mathrm{C}$ [15]. This attribute makes it an ideal model for studying the cold-tolerance mechanisms of plants. Several cold-related genes have been identified in A. mongolicus, including AmCBL1 [7], AmLEA [8], and $A m C I P$ [11]. However, for woody plants, the available genetic resources are not sufficient to determine the mechanisms of cold tolerance.

Few studies have performed transcriptome sequencing of A. mongolicus. Zhou et al. identified putative genes associated with drought tolerance using 454 pyrosequencing [33]. Compared with this alternative next-generation method, solexa has the advantages of lower cost and generation of larger amounts of data [17]. Moreover, using the recently developed Trinity software, any disadvantages related to 


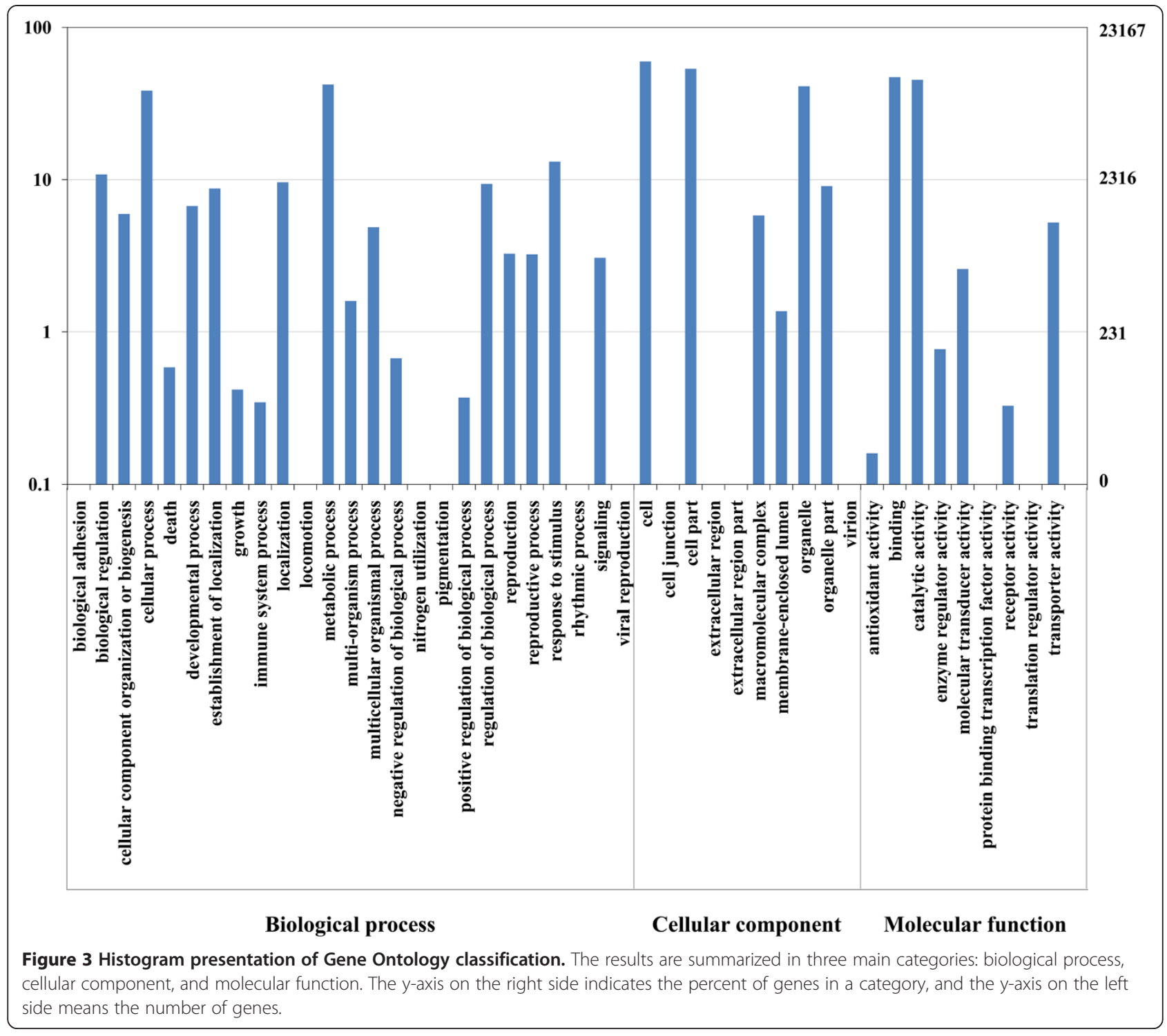

short reads can be overcome, resulting in the assembly of transcriptome results without a reference genome being as reliable as those with an available reference genome [29].

During cold acclimation, plants receive low temperature signals and initiate a defense mechanism, including physical structure adaptations (changes in lipid composition), increases in intercellular osmoprotectants (such as soluble sugars, proline and betaine), and increased synthesis of anti-oxidants (superoxide dismutase, catalase and ascorbic acid reductase), enabling restoration of the balance of matter synthesis and energy metabolism and enhancing survival in colder environments [30,34]. Furthermore, expression patterns of a large number of genes during cold acclimation have been detected using gene chip and microarray technologies [35,36]. Use of transcriptome sequencing during cold acclimation will increase our understanding of the cold tolerance mechanisms of plants.
The amount of data obtained from transcriptome sequencing varies according to the transcriptome size of the species. However, the transcriptome size is affected by both gene number and abundance, and varies markedly among species. Our estimate of the nuclear genome size of $A$. mongolicus $(2 \mathrm{n}=18)$ using flow cytometry was $2 \mathrm{C}=$ $1639.12 \pm 15.22 \mathrm{Mb}$. In this study, the total length of the reads from both samples was $\sim 11.9$ gigabases $(\mathrm{Gb})$. This is the first report of the genome size of Ammopiptanthus mongolicus.

\section{Membrane systems}

Membrane systems, which are known to be the primary site of freezing injury in plants, suffer multiple forms of damage caused by freeze-induced cellular dehydration [37]. During cold acclimation, plants experience improved cold tolerance with increased concentrations of unsaturated fatty acids and 


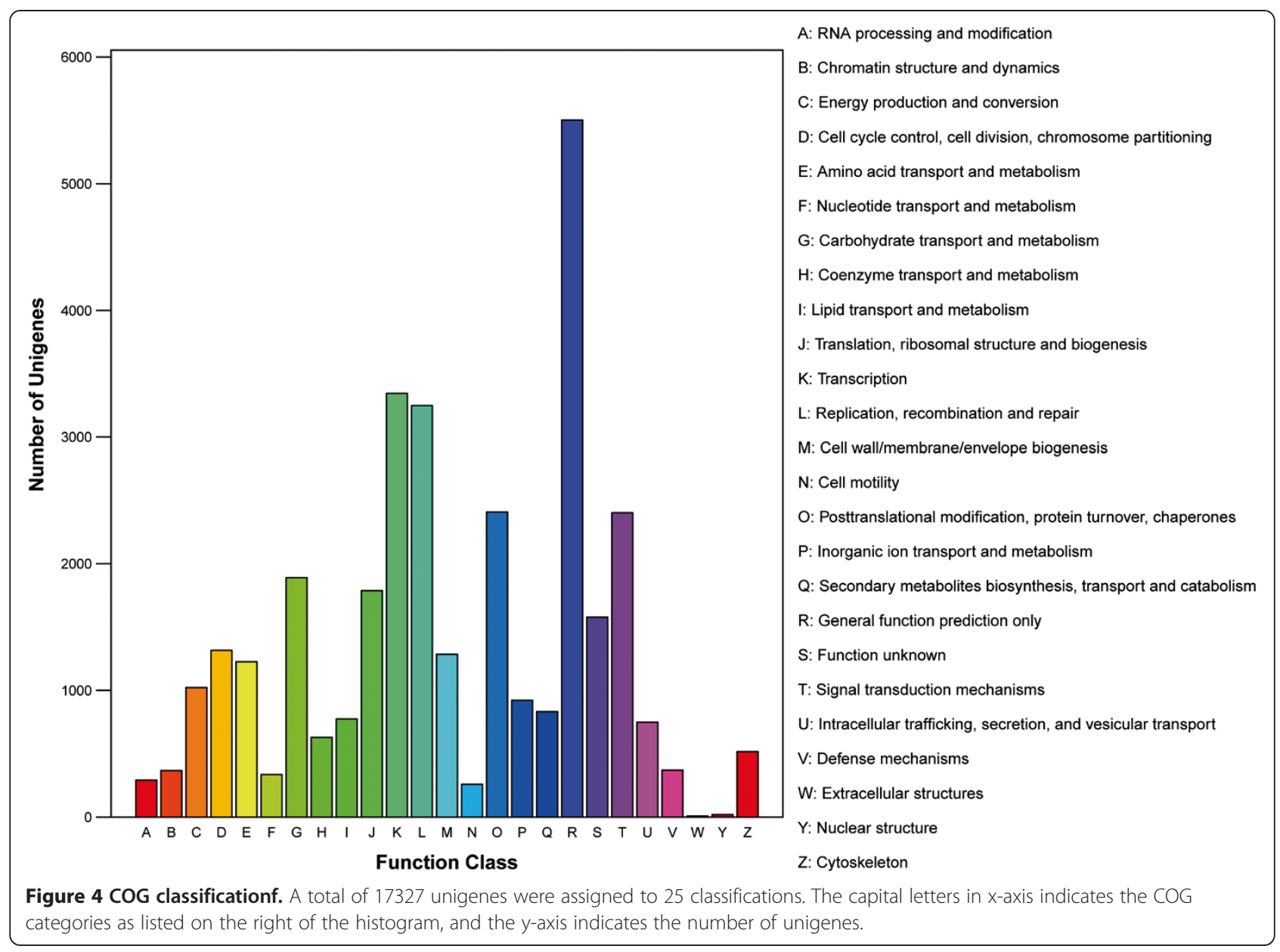

phospholipids [38]. We identified a total of 773 genes $(4.46 \%)$ involved in "Lipid transport and metabolism" according to the COG classification. Moreover, according to the metabolic pathway enrichment analysis, eight pathways, including "Biosynthesis of unsaturated fatty acids" (Ko01040), were involved in lipid metabolism. Increases in the biosynthesis of unsaturated fatty acids improve cold defense and prevent damage caused by low temperatures [39]. Nine genes in this process showed significant upregulation in transcripts after cold stress. For example, the fatty acid desaturase 8 (FAD8) gene (CL23852. Contig1_All) was upregulated by 1.62 -fold. The FAD8 gene in $A$. thaliana encodes chloroplast membrane-associated $\omega$ 3 desaturase, which contributes to freezing tolerance by altering the lipid composition [40].

\section{Intercellular osmoprotectant}

Proline, one of the most important organic osmolytes, participates in the responses to various environmental stresses [41]. As a hydrophilic protein, proline can relieve the osmotic stress caused by cold-induced dehydration. Two genes (CL407.Contig3_All and CL31553.COntig1_All) encoding delta-1-pyrroline-5-carboxylate synthase (P5CS) were to be significantly upregulated by 1.42 - and 3.82-fold after cold stress, respectively. As a key enzyme in proline synthesis, P5CS participates in the cold-stress response and shows high expression, which promotes the synthesis of proline for cold tolerance $[42,43]$. The accumulation of sucrose and other simple sugars also contributes to the stabilization of membranes, as these molecules protect membranes against freeze-induced damage in vitro [44]. Three LEA (late embryogenesis abundant)-related genes (CL36265.Contig1_All, CL30168.Contig1_All) were also examined with fold changes in their expression ranging from 3.37 to 5.64. The LEA protein functions as an antioxidant, as well as a membrane and protein stabilizer, during water stress [45]. In $A$. mongolicus and other legumes, recent studies have suggested that novel hydrophilic and LEA polypeptides stabilize membranes against freeze-induced injury $[8,46]$.

\section{Antioxidant enzyme system}

When plants are under cold stress, reactive oxygen species (ROS) accumulate. These are harmful to both the membrane and related biological macromolecules [47]. During cold acclimation, the antioxidant enzyme system of plants is enhanced in response to the increased stress [48]. $A$. 


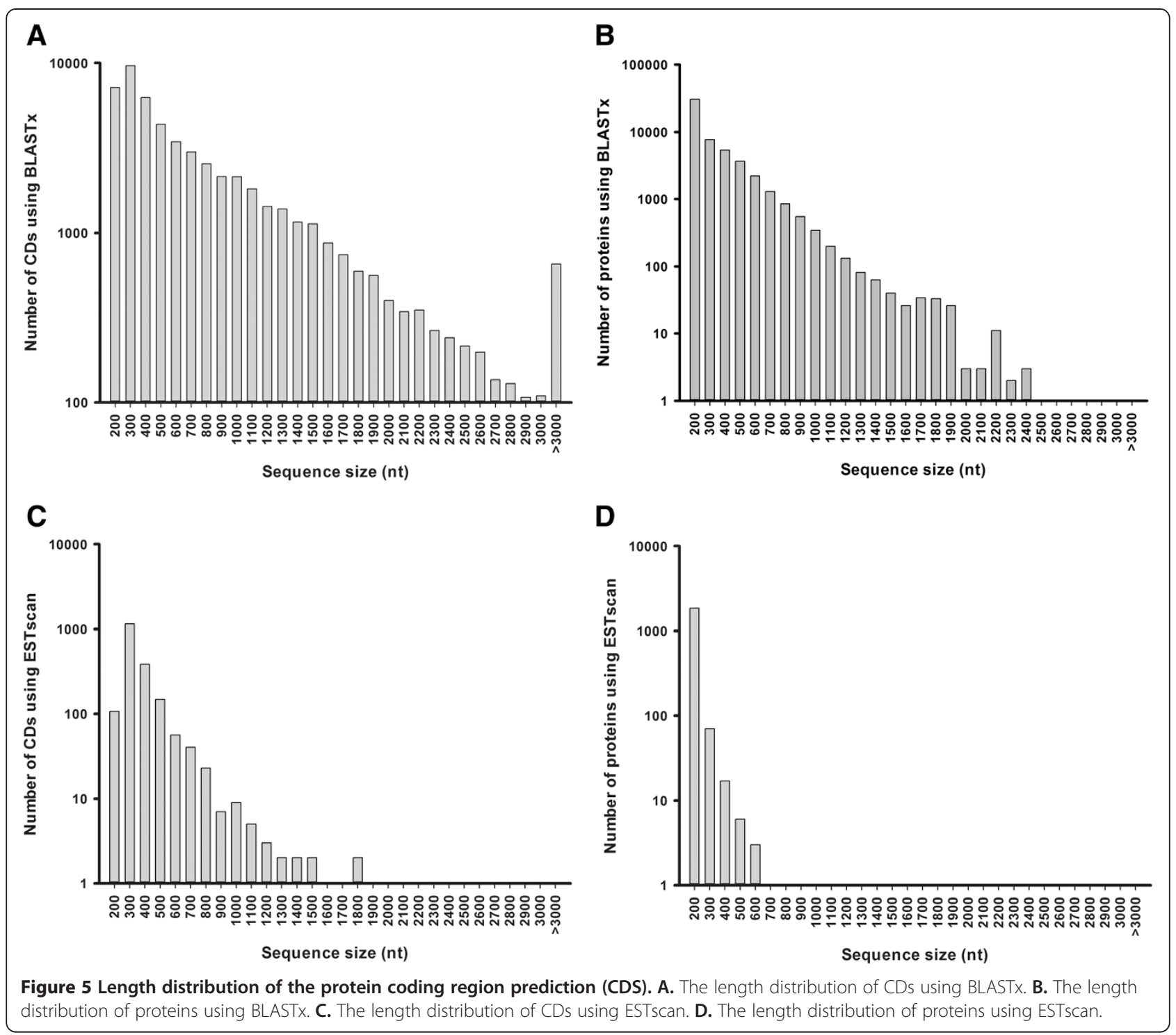

mongolicus can maintain efficient growth in extremely stressful environments, which makes it a valuable natural resource and strong antioxidant [5]. The expression profiles of seven ROS-scavenging enzyme genes ( $A m S O D, A m A P X$, AmGPX, AmCAT, AmGLR, AmPrx, and AmTrx) in A. mongolicus were reported by Shi et al. and AmCAT and $A m S O D$ showed high expression levels [49]. In our study, a total of 830 DEGs were related to the GO term "oxidoreductase activity", 186 of which were up-regulated. Among them, we identified 20 genes in the peroxisome pathway, including two (CL33833.Contig1_All and Unigene5521_All) encoding CAT (catalase) and one (Unigene12648_All) encoding SOD (superoxide dismutase) with the fold changes of 2.84, 1.42, and 4.50, respectively. In rice, CAT plays an important role in cold acclimation, and the accumulation of SODs can reduce cold injury [50].

\section{$\mathrm{Ca}^{2+}$ and $\mathrm{ABA}$}

As an important second messenger, $\mathrm{Ca}^{2+}$ is known to play a role in the plant cold-stress response. The concentration of $\mathrm{Ca}^{2+}$ increases rapidly during cold stress, followed by a series of signals mediated by a combinations of protein phosphorylation/dephosphorylation cascades [51]. As a large subfamily of plant kinases, Calcium dependent protein kinase (CDPKs) are implicated as important sensors of $\mathrm{Ca}^{2+}$ flux in plants in response to a variety of biotic and abiotic stress stimuli [52]. We have identified three genes (Unigene567_All, Unigene13378_All, Unigene13204_All) related to $\mathrm{CDPK}$, with fold changes ranging from 1.96 to 3.14 in their expression after cold stress. Abscisic acid (ABA) also plays a crucial role in the cold acclimation of plants. Cold acclimation has been reported to be involved in both ABA-dependent and -independent pathways 


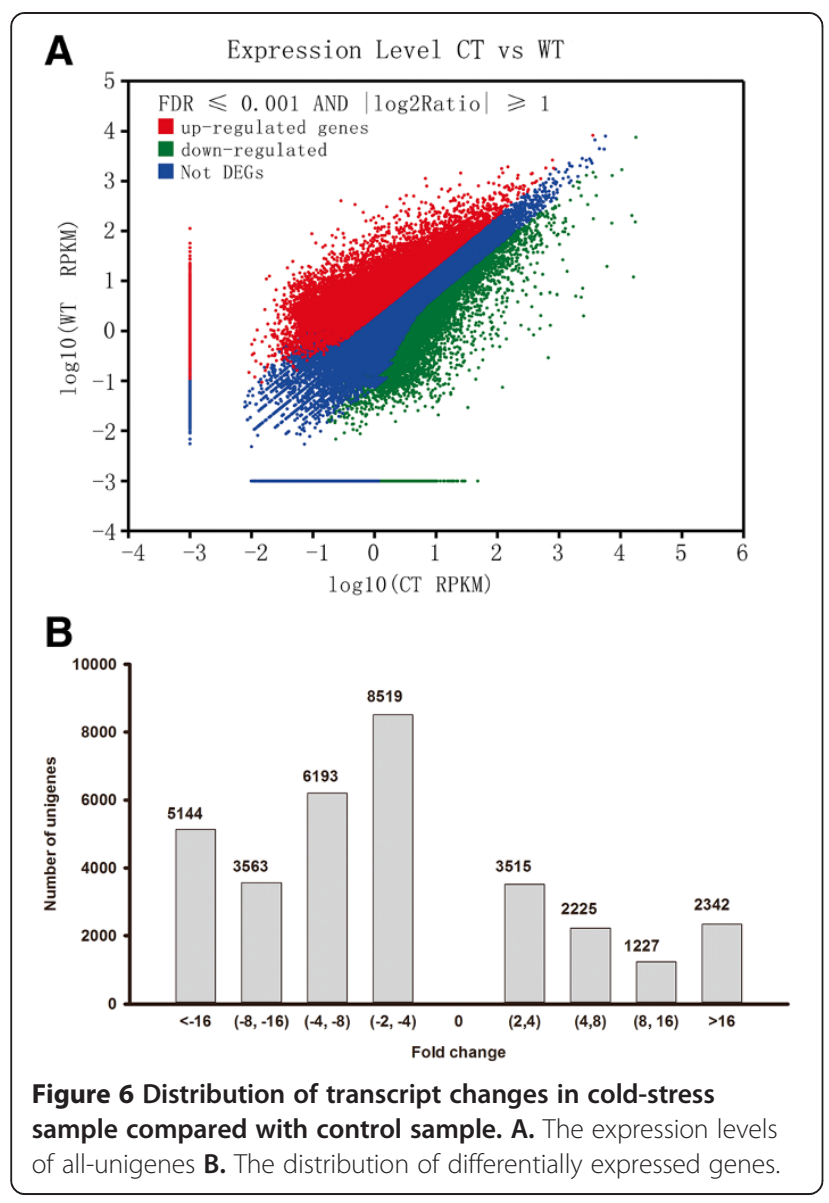

[53,54]. The type $2 \mathrm{C}$ protein phosphatases (PP2C) ABI1 and $\mathrm{ABI} 2$, which negatively regulate $\mathrm{ABA}$ responses, play a key role in ABA signal transduction [55]. In our study, eight DEGs (Unigene22945_All, Unigene30641_ All, Unigene34701_All, CL2188.Contig1_All, CL1877. Contig1_All, CL16627.Contig1_All, CL10137.Contig1_All, and CL28715.Contig1_All) related to PP2C were identified, showing significant down-regulation with fold changes ranging from -2.3 to -12.5 in their expression after cold stress. The function of ABA-activated SnRK2 protein kinase has also been reported in dehydration stress signaling in Arabidopsis [56,57]. One gene (Unigene3661_All) related to SnRK2 was identified with a fold change of 2.4. On the other hand, two genes related to SnRK2 in A. mongolicus were reported by Zhou et al., with fold changes of 1.89 and 3.75, respectively, after drought exposure for $72 \mathrm{~h}$ [33]. Therefore, it is likely that the SnRK2 gene of A. mongolicus shows an expression pattern under cold stress similar to that under drought stress. We also identified PLD $\alpha 1$, PLD $\beta 1$ and PLD $\delta$ to be up-regulated (fold changes of 1.20, 1.18 and 1.93, respectively). These genes are believed to function in ABA signaling in guard cells $[58,59]$.

\section{Cold-related genes and transcription factors}

We last focused on changes in the expression of genes associated with transcription factors. A total of 720 of 1636 unigenes were identified as DEGs, 209 of which showed significant upregulation. Most of these unigenes had homologs in other legumes, such as Glycine max, Medicago truncatula and Lotus japonicas, which are known to be stress-induced, such as the ERF and WRKY families. These up-regulated transcription factors may play important roles in plant defense and stress responses [60]. Some cold-related genes identified by Thomashow [31], such as COR, LEA, CBF, and DREB, have been cloned and identified by qRT-PCR showing the same trend as our Illumina/Solexa sequencing.

\section{Conclusions}

This is the first report of transcriptome sequencing of $A$. mongolicus under cold acclimation using Illumina/ Solexa. The total length of the reads was $\sim 11.9 \mathrm{~Gb}$. A total of 82795 unigenes were assembled, 32728 of which were differently expressed with 9309 unigenes showing up-regulation. By performing BLAST analysis of the allunigenes against public databases (Nr, Swiss-Prot, KEGG and $\mathrm{COG}$ ), we obtained functional annotations and classifications. The large number of transcriptomic sequences and their functional annotations provide sufficient resources for molecular studies of $A$. mongolicus. Moreover, information on the KEGG metabolic pathways and transcription factors will facilitate the discovery of other cold resistant genes.

\section{Methods}

\section{Plant materials}

A. mongolicus seeds were collected from AlaShan Desert in Inner Mongolia, Northwest China. After sterilization and seeding in hormone-free Murashige and Skoog medium for 30 days, the seedlings were moved and cultured at room temperature (approximately $20^{\circ} \mathrm{C}$ ), with a photoperiod of $16 \mathrm{~h}$ light and $8 \mathrm{~h}$ dark. Two weeks after transplanting, we divided the plantlets into two groups. The first group served as the control sample (CK), while the other was moved and cultured at $4^{\circ} \mathrm{C}$ as the coldtreated sample $(\mathrm{CT})$. Both samples were planted in the nursery of Beijing Forestry University (BJFU) $\left(116.3^{\circ} \mathrm{E}\right.$, $40.0^{\circ} \mathrm{N}$ ), and watered every three days. Leaves and roots of both samples were collected simultaneously after treatment for 14 days and rapidly stored at $-80^{\circ} \mathrm{C}$ until required for RNA extraction.

\section{Nuclear DNA content determination}

The cotyledons of $A$. mongolicus were collected from the plants from which the leaves and roots for sequencing were obtained. Cotyledons were homogenized in 2-mL homogenization buffer (45 mM $\mathrm{MgCl}_{2} ; 30 \mathrm{mM}$ sodium; 
Table 3 Statistical enrichment analysis for KEGG metabolic pathways $(p \leq 0.05)$

\begin{tabular}{|c|c|c|c|c|c|}
\hline \multirow[t]{3}{*}{ Pathway ID } & \multirow[t]{3}{*}{ Pathway } & \multicolumn{3}{|c|}{ Genes with pathway annotation } & \multirow{3}{*}{$p$ value } \\
\hline & & \multirow[t]{2}{*}{ All genes } & \multicolumn{2}{|c|}{ DEGs } & \\
\hline & & & Up & Down & \\
\hline ko01100 & Metabolic pathways & $5905(21.49 \%)$ & 607 & 2004 & 9.37E-18 \\
\hline ko01110 & Biosynthesis of secondary metabolites & $2821(10.27 \%)$ & 322 & 989 & 4.54E-16 \\
\hline \multicolumn{6}{|c|}{ Carbohydrate metabolism } \\
\hline ko00040 & Pentose and glucuronate interconversions & $233(0.85 \%)$ & 31 & 130 & $3.28 \mathrm{E}-20$ \\
\hline ko00500 & Starch and sucrose metabolism & $651(2.37 \%)$ & 72 & 257 & 3.70E-09 \\
\hline ko00053 & Ascorbate and aldarate metabolism & $208(0.76 \%)$ & 21 & 80 & 0.004397 \\
\hline ko00010 & Glycolysis / Gluconeogenesis & $337(1.23 \%)$ & 31 & 119 & 0.03086 \\
\hline ko00660 & C5-Branched dibasic acid metabolism & $11(0.04 \%)$ & 5 & 3 & 0.026546 \\
\hline ko00620 & Pyruvate metabolism & $247(0.9 \%)$ & 20 & 94 & 0.017667 \\
\hline \multicolumn{6}{|c|}{ Amino acid metabolism } \\
\hline ko00360 & Phenylalanine metabolism & $214(0.78 \%)$ & 23 & 92 & $1.42 \mathrm{E}-05$ \\
\hline ko00270 & Cysteine and methionine metabolism & $225(0.82 \%)$ & 34 & 78 & 0.000967 \\
\hline ko00250 & Alanine, aspartate and glutamate metabolism & $171(0.62 \%)$ & 21 & 63 & 0.006038 \\
\hline ko00300 & Lysine biosynthesis & $39(0.14 \%)$ & 5 & 21 & 0.000519 \\
\hline ko00290 & Valine, leucine and isoleucine biosynthesis & $90(0.33 \%)$ & 16 & 33 & 0.00268 \\
\hline ko00380 & Tryptophan metabolism & $116(0.42 \%)$ & 19 & 42 & 0.002663 \\
\hline ko00260 & Glycine, serine and threonine metabolism & $139(0.51 \%)$ & 16 & 52 & 0.013956 \\
\hline ko00330 & Arginine and proline metabolism & $167(0.61 \%)$ & 25 & 52 & 0.045321 \\
\hline \multicolumn{6}{|c|}{ Metabolism of other amino acids } \\
\hline ko00460 & Cyanoamino acid metabolism & $167(0.61 \%)$ & 23 & 71 & 7.09E-06 \\
\hline \multicolumn{6}{|c|}{ Biosynthesis of other secondary metabolites } \\
\hline ko00940 & Phenylpropanoid biosynthesis & $483(1.76 \%)$ & 57 & 201 & 2.29E-10 \\
\hline ko00941 & Flavonoid biosynthesis & $272(0.99 \%)$ & 29 & 124 & $1.24 \mathrm{E}-08$ \\
\hline ko00945 & Stilbenoid, diarylheptanoid and gingerol biosynthesis & $241(0.88 \%)$ & 39 & 96 & $1.20 \mathrm{E}-07$ \\
\hline ko00944 & Flavone and flavonol biosynthesis & $78(0.28 \%)$ & 8 & 37 & 0.000808 \\
\hline ko00966 & Glucosinolate biosynthesis & $40(0.15 \%)$ & 11 & 16 & 0.000298 \\
\hline ko00402 & Benzoxazinoid biosynthesis & $43(0.16 \%)$ & 3 & 24 & 0.001612 \\
\hline ko00950 & Isoquinoline alkaloid biosynthesis & $40(0.15 \%)$ & 5 & 18 & 0.015469 \\
\hline \multicolumn{6}{|c|}{ Energy metabolism } \\
\hline ko00195 & Photosynthesis & $113(0.41 \%)$ & 4 & 72 & 1.86E-09 \\
\hline \multicolumn{6}{|c|}{ Lipid metabolism } \\
\hline ko00592 & alpha-Linolenic acid metabolism & $156(0.57 \%)$ & 20 & 67 & 2.46E-05 \\
\hline ko01040 & Biosynthesis of unsaturated fatty acids & $94(0.34 \%)$ & 9 & 44 & 0.000624 \\
\hline ko00565 & Ether lipid metabolism & $675(2.46 \%)$ & 83 & 215 & 0.006119 \\
\hline ko00062 & Fatty acid elongation & $6(0.02 \%)$ & 2 & 4 & 0.003736 \\
\hline ko00564 & Glycerophospholipid metabolism & $866(3.15 \%)$ & 110 & 273 & 0.001839 \\
\hline ko00100 & Steroid biosynthesis & $80(0.29 \%)$ & 9 & 31 & 0.034756 \\
\hline ko00591 & Linoleic acid metabolism & $76(0.28 \%)$ & 5 & 35 & 0.013071 \\
\hline ko00071 & Fatty acid metabolism & $136(0.49 \%)$ & 11 & 56 & 0.012113 \\
\hline \multicolumn{6}{|c|}{ Metabolism of cofactors and vitamins } \\
\hline ko00785 & Lipoic acid metabolism & $11(0.04 \%)$ & 0 & 9 & 0.005247 \\
\hline ko00770 & Pantothenate and CoA biosynthesis & 79 (0.29\%) & & & 0.045586 \\
\hline
\end{tabular}


Table 3 Statistical enrichment analysis for KEGG metabolic pathways ( $p \leq 0.05)$ (Continued)

\begin{tabular}{|c|c|c|c|c|c|}
\hline \multicolumn{6}{|c|}{ Metabolism of terpenoids and polyketides } \\
\hline ko00904 & Diterpenoid biosynthesis & $98(0.36 \%)$ & 10 & 55 & $6.17 \mathrm{E}-08$ \\
\hline ko00903 & Limonene and pinene degradation & $205(0.75 \%)$ & 33 & 83 & 4.46E-07 \\
\hline ko00906 & Carotenoid biosynthesis & $195(0.71 \%)$ & 25 & 85 & 1.07E-06 \\
\hline ko00908 & Zeatin biosynthesis & $312(1.14 \%)$ & 41 & 113 & 0.000209 \\
\hline ko00902 & Monoterpenoid biosynthesis & $30(0.11 \%)$ & 13 & 26 & 0.01791 \\
\hline \multicolumn{6}{|c|}{ Glycan Biosynthesis and Metabolism } \\
\hline ko00531 & Glycosaminoglycan degradation & $86(0.31 \%)$ & 5 & 39 & 0.017583 \\
\hline \multicolumn{6}{|c|}{ Immune system } \\
\hline ko04650 & Natural killer cell mediated cytotoxicity & $123(0.45 \%)$ & 23 & 42 & 0.00168 \\
\hline \multicolumn{6}{|c|}{ Signal Transduction } \\
\hline ko04075 & Plant hormone signal transduction & $1667(6.07 \%)$ & 185 & 614 & 1.87E-13 \\
\hline \multicolumn{6}{|c|}{ Environmental Adaptation } \\
\hline ko04626 & Plant-pathogen interaction & $1719(6.26 \%)$ & 139 & 693 & $3.34 \mathrm{E}-15$ \\
\hline
\end{tabular}

20 mM MOPS; 0.1\% (w/v) TritonX-100; pH 7.0) [61] and filtered through a 300-mesh nylon netting. The nuclei suspension was obtained by centrifuging the suspension at $1100 \mathrm{rpm}$ for $6 \mathrm{~min}$. After staining with propidium iodide (PI, $50 \mu \mathrm{g} / \mathrm{mL}$ ) and incubating at $4^{\circ} \mathrm{C}$ for $20 \mathrm{~min}$, nuclei were examined by flow cytometry.
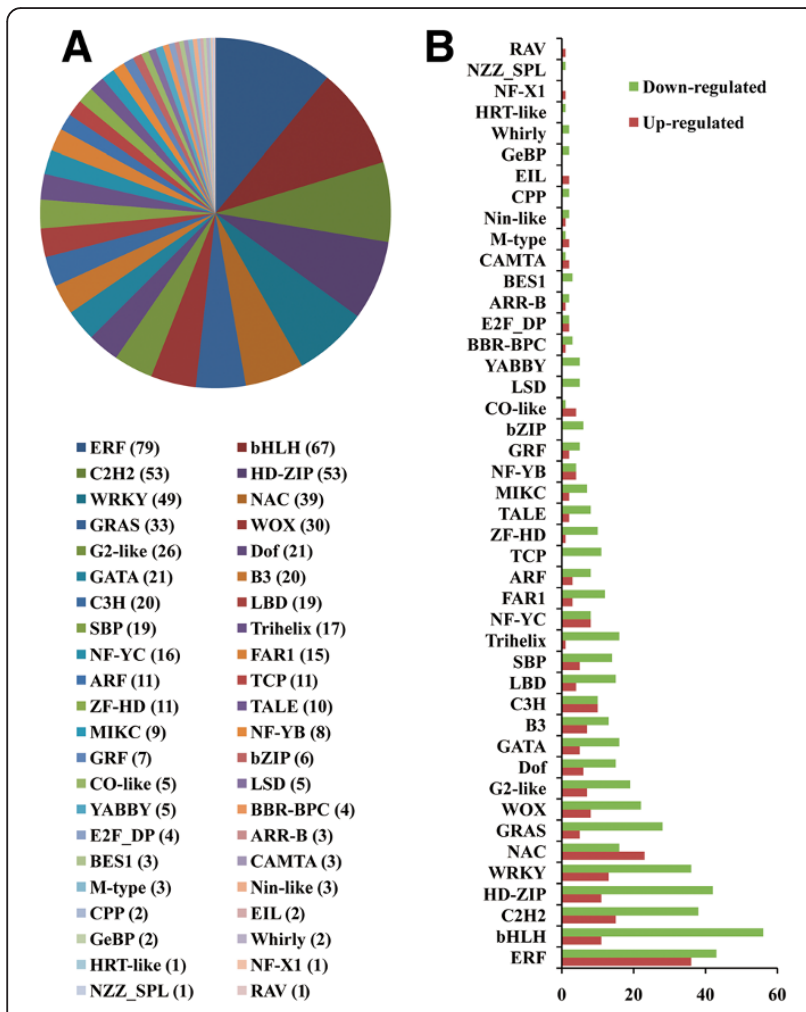

Figure 7 Distribution of transcription factors in gene families.

A. The distribution of transcription factors according to the gene family information. B. DEGs from every gene family involved in transcription.
The standard sample was young healthy leaves from 1week-old maize seedlings (Zea mays L.) (Zheng Dan 958). Three measurements per sample were obtained.

\section{RNA extraction and quality determination}

Total RNA of each sample was extracted three times using a CTAB procedure [62]. Leaves and roots of each sample were extracted separately and mixed with equal amounts of mRNA after examination. The RNA samples were dissolved in $10 \mathrm{mM}$ Tris ( $\mathrm{PH} \mathrm{7.6)}$ and examined using the NanoDrop ND-8000; the $\mathrm{A}_{260} / \mathrm{A}_{280}$ ratios of both samples ranged from 1.9 to 2.1. The integrity of the RNA samples was assessed with an Agilent 2100 Bioanalyzer; no sign of degradation was found.

\section{cDNA library construction and sequencing}

For the synthesis of cDNA and Solexa sequencing, we prepared $45 \mu \mathrm{g}$ of total RNA for treated and control sample at concentrations of approximately $1500 \mathrm{ng} / \mu \mathrm{l}$. We then enriched the poly (A) mRNA using beads with Oligo (dT) and interrupted mRNA into short fragments with fragmentation buffer. Using these short fragments as templates, we synthesized first-strand cDNA with hexamer-primers and reverse transcriptase (Invitrogen). The second-strand cDNA was synthesized using buffer, dNTPs, RNaseH (Invitrogen) and DNA polymerase I (New England BioLabs). The short fragments were then purified using a QiaQuick PCR extraction kit and resolved with EB buffer to finish the end reparation, and were connected using sequencing adaptors. After resolution by agarose gel electrophoresis, we selected fragments suitable for PCR amplification. We then constructed two paired-end libraries which were sequenced using an Illumina HiSeq 2000. 
Table 4 Real-time RT-PCR with putative unique transcripts (PUTs)

\begin{tabular}{|c|c|c|c|}
\hline $\begin{array}{l}\text { Putative unique } \\
\text { transcript ID }\end{array}$ & Annotation (BLASTX) & $\begin{array}{l}\text { Relative gene } \\
\text { expression } \\
\text { by qRT-PCR } \\
\left(2^{-\Delta \Delta C T}\right)\end{array}$ & $\begin{array}{l}\text { Expression difference } \\
\text { analysis of Illumina/ } \\
\text { Solexa (Log2(CT_RPKM/ } \\
\text { WT_RPKM)) }\end{array}$ \\
\hline Unigene3649_All & CBF3 protein [Glycine max] & $2.11 \pm 0.18$ & 7.8564 \\
\hline Unigene5045_All & PREDICTED: uncharacterized protein LOC100795990 isoform 1 [Glycine max] & $2.64 \pm 0.51$ & 2.1173 \\
\hline CL9479.Contig1_All & ICE-like protein [Corylus heterophylla] & $1.90 \pm 0.40$ & 2.2465 \\
\hline Unigene2612_All & PREDICTED: probable transcription factor PosF21-like [Glycine max] & $2.70 \pm 0.67$ & 4.3792 \\
\hline CL26498.Contig1_All & Basic leucine zipper transcription factor [Medicago truncatula] & $4.30 \pm 2.79$ & 2.0836 \\
\hline Unigene12211_All & PREDICTED: microtubule-associated protein 70-5-like [Glycine max] & $2.82 \pm 0.11$ & 2.9144 \\
\hline CL25117.Contig1_All & Cold acclimation protein COR413-PM1 [Medicago truncatula] & $3.51 \pm 0.32$ & 2.9919 \\
\hline CL33467.Contig1_All & PREDICTED: sugar transporter ERD6-like 5-like [Glycine max] & $2.44 \pm 0.27$ & 1.9228 \\
\hline Unigene12905_All & PREDICTED: LOW QUALITY PROTEIN: sugar transporter ERD6-like 16-like [Glycine max] & $12.59 \pm 7.89$ & 10.7104 \\
\hline CL21996.Contig1_All & PREDICTED: cysteine proteinase RD19a-like [Glycine max] & $1.78 \pm 0.10$ & 1.2868 \\
\hline Unigene28735_All & Medicago truncatula HVA22-like protein a (MTR_4g108350) mRNA, complete cds & $2.35 \pm 0.28$ & 2.107 \\
\hline Unigene5543_All & HVA22-like protein e [Medicago truncatula] & $9.91 \pm 2.45$ & 6.7199 \\
\hline Unigene6814_All & PREDICTED: HVA22-like protein k-like [Glycine max] & $7.02 \pm 0.32$ & 2.8637 \\
\hline Unigene37576_All & PREDICTED: low-temperature-induced 65 kDa protein-like [Glycine max] & $2.78 \pm 1.34$ & 7.4373 \\
\hline CL11725.Contig1_All & PREDICTED: low-temperature-induced $65 \mathrm{kDa}$ protein-like [Glycine max] & $2.16 \pm 0.17$ & 7.5431 \\
\hline CL5093.Contig1_All & Hydrophobic protein LTI6B [Medicago truncatula] & $2.12 \pm 0.10$ & 3.8777 \\
\hline Unigene5480_All & Hydrophobic protein RCI2A [Arabidopsis thaliana] & $4.32 \pm 0.32$ & 5.8638 \\
\hline CL26053.Contig1_All & PREDICTED: hydrophobic protein LTI6A-like [Glycine max] & $3.43 \pm 0.26$ & 1.5422 \\
\hline Unigene37577_All & PREDICTED: low-temperature-induced $65 \mathrm{kDa}$ protein-like [Glycine max] & $3.53 \pm 1.07$ & 6.5686 \\
\hline CL30168.Contig1_All & seed maturation protein [Glycine tomentella] & $7.42 \pm 0.88$ & 3.3724 \\
\hline
\end{tabular}

Raw reads produced from sequencing machines contain low-quality reads, which negatively affect subsequent bioinformatics analyses. Therefore, we discarded the these reads, including those with adaptors, those with unknown nucleotides larger than $5 \%$ and those of low quality $(<20 \%$ of the bases with a quality score $Q \leq 10$ ) using an in-house Perl script. The average proportion of clean reads in each sample was $\sim 91.5 \%$, on which the following analysis was based.

\section{De novo assembly and assessment}

Transcriptome de novo assembly was performed using the short-reads assembly program, Trinity [29], which first combined reads with certain lengths of overlap to form longer fragments, known as contigs. These reads were then mapped back to contigs. Using paired-end reads, we detected contigs from the same transcript as well as the distances between these contigs. Next, we used Trinity to connect the contigs and obtained sequences that cannot be extended on either end, known as unigenes. Finally, we used TGICL [63], a software system for rapid clustering of large EST datasets, to assemble all the unigenes from both samples to form a single set of non-redundant unigenes.
After clustering, the unigenes were divided into two classes: clusters and singletons. Finally, BLASTx alignment $(\mathrm{E}$-value $<0.00001)$ was performed between unigenes and the protein databases, following the priority order: Nr, Swiss-Prot, KEGG and COG. The best alignment results were used to decide the sequence direction of unigenes. For unigenes that could not be aligned to any of the above databases, we used ESTScan to determine the sequence direction.

\section{Functional annotation}

We aligned the unigene sequences to the above-mentioned protein databases by BLASTx $(\mathrm{E}$-value $<0.00001)$ and to the nucleotide sequence database $\mathrm{Nt}(\mathrm{E}$-value $<0.00001)$ by BLASTn. We thus obtained proteins with the highest similarity to the given unigenes, as well as the functional annotations.

According to the $\mathrm{Nr}$ annotation, we obtained the GO functional annotation using the Balst2GO program [64], and the GO functional classification for all-unigenes using the WEGO software [65] to understand the distribution of gene functions of the species from the macro-level. After aligning the all-unigenes to the COG database, we obtained the COG functional annotations. Next, we further examined the complex biological behaviors. To investigate the 
metabolic pathway annotation of unigenes, we aligned the all-unigenes to the KEGG database [66], and so obtained pathway annotations.

\section{Protein-coding region prediction}

To predict the protein-coding regions, unigenes were aligned to the protein databases in the abovementioned priority order. The coding regions of proteins with the highest ranks based on the BLAST results were determined, and the coding region sequences were translated into amino acid sequences using the standard codon table. Both the nucleotide $\left(5^{\prime}-3^{\prime}\right)$ and amino acid sequences of the unigenecoding region were acquired. Unigenes that could not be aligned to any of the above databases were scanned by ESTScan [67] to determine the sequence $\left(5^{\prime}-3^{\prime}\right)$ direction and amino acid sequences of the predicted coding region.

\section{Differential expression analysis of unigenes}

To identify those whose levels of expression differed, we performed a differential expression analysis of the unigenes. RPKM (reads per kb per million reads) [68] was used to calculate unigene expression levels, which eliminated the influence of gene length and sequencing level on the calculation of gene expression. The RPKM method formula was:

$$
R P K M=\frac{10^{6} C}{N L / 10^{3}}
$$

where $C$ is the number of reads that uniquely aligned to one unigene; $N$ is the total number of reads that uniquely aligned to all unigenes; $L$ is the base number in the CDS of one unigene.

Based on the method described by Audic and Claverie [69], we determined the statistical significance of differential expression profile for each gene. FDR (False Discovery Rate) control method [70] was used in multiple hypothesis testing to correct the results for $p$ value. After the FDR was obtained, we used the ratio of RPKMs to calculate the fold-change in the expression of each gene in two samples simultaneously. In our analysis, the differentially expressed genes (DEGs) were screene with the threshold of FDR $\leq 0.001$ and the absolute value of $\log 2$ Ratio $\geq 1$ [71].

We then mapped all DEGs to each term of Gene Ontology database (http://www.geneontology.org/) and calculated the gene numbers each GO term had, and got a gene list and gene numbers for every certain GO term. Then using hypergeometric test [72], we found significantly enriched GO terms in DEGs comparing to the genome background of $A$. mongolicus. The calculated $p$ value went through Bonferroni Correction, taking corrected $p$ value $\leq 0.05$ as a threshold. GO terms fulfilling this condition were defined as significantly enriched GO terms in DEGs. $P$ value formula was:

$$
P=1-\sum_{i=0}^{m-1} \frac{\left(\begin{array}{l}
M \\
i
\end{array}\right)\left(\begin{array}{l}
N-M \\
n-i
\end{array}\right)}{\left(\begin{array}{l}
N \\
n
\end{array}\right)}
$$

where $N$ is the number of all genes with GO annotation; $n$ is the number of DEGs in $N ; M$ is the number of all genes that are annotated to the certain GO terms; $m$ is the number of DEGs in $M$.

DEGs were also used in pathway enrichment analysis. We calculated the gene numbers in each pathway by mapping all DEGs to KEGG database (http://www.genome.jp/kegg). By comparing with the whole genome background of $A$. mogolicus, pathways with $p \leq 0.05$ were chosen as significantly enriched in DEGs, using the same multiple testing correction method with GO enrichment analysis. With pathway enrichment analysis, we got the main biochemical pathways and signal transduction pathways in which DEGs involved. Some cold stress related pathways were listed, on which all following analyses and discussions based.

\section{Transcription factors analysis}

Transcription factors were predicted according to protein sequences obtained from CDS prediction. We used hmmsearch to search the domain of the plant transcription factors (http://plntfdb.bio.uni-potsdam.de/ $\mathrm{v} 3.0 /$ ) and classified unigenes according to the gene family information. Genes that were believed to be associated with cold stress were selected for further investigation.

\section{Quantitative real-time PCR analysis}

The unigenes selected were then assessed by quantitative real-time PCR. Approximately $1 \mu \mathrm{g}$ of total RNA of each sample was converted into single-stranded cDNA using M-MLV Reverse Transcriptase (Progema, USA). The cDNA products were then diluted 100-fold with deionized water before use as a template. The reaction was performed on a STEP ONE PLUS ${ }^{\text {тм }}$ Real-Time PCR System (Applied Biosystems, USA) using the RealMasterMix (SYBR Green) (China). The reaction system $(20 \mu \mathrm{L})$ contained $9-\mu \mathrm{L} 2.5 \times$ RealMasterMix/20 $\times$ SYBR Solution, $1 \mu \mathrm{L}$ of each of the forward and reverse primers and $1-\mu \mathrm{L}$ cDNA template. The reaction was performed under the following conditions: $94^{\circ} \mathrm{C}$ for $2 \mathrm{~min}$, followed by 45 cycles of $94^{\circ} \mathrm{C}$ for $20 \mathrm{~s}, 60^{\circ} \mathrm{C}$ for $35 \mathrm{~s}$ and $68^{\circ} \mathrm{C}$ for $1 \mathrm{~min}$. Three independent biological replicates were performed for each sample. Expression levels of the selected unigenes were normalized to that 
of $18 \mathrm{~S}$ rRNA, an internal reference gene. Relative gene expression levels were calculated using the $2^{-\Delta \Delta \mathrm{Ct}}$ [73]. The primer sequences used for qRT-PCR are listed in Additional file 4.

\section{Additional files}

Additional file 1: 100 most abundant transcripts in both samples. The list of 100 most abundant transcripts in both cold-treated sample (CT) and control sample (CK). The $\mathrm{Nr}$ annotations of each gene-ID were also listed.

\section{Additional file 2: Genes that expressed only under cold treated.}

The list of genes that expressed only under cold treated. The gene length, raw reads, as well as functional annotation of several public databases were also listed.

Additional file 3: $\mathrm{GO}$ enrichment analysis. The list of the $\mathrm{GO}$ enrichment analysis results. $\mathrm{GO}$ terms with a corrected $p$ value $\leq 0.05$ were defined as significantly enriched in DEGs.

Additional file 4: Primer sequences for qRT-PCR. The primers used in quantitative real-time $P C R$ analysis.

\section{Competing interest}

The authors declare that they have no competing interests.

\section{Authors' contributions}

WLY and XLX conceived this study. TP designed the experimental plan. TP and CYY participated in sample collection, RNA preparation and analyzed the sequence data. All authors read and approved the final manuscript.

\section{Acknowledgements}

We thank Lili Guo, Sha Tang, Jinhuan Chen, Peng Shuai and Dongchao Zheng for their insightful comments on the experiments. The research was supported by grants from the Ministry of Science and Technology of China (2011BAD38B01, 2009CB119101), the National Natural Science Foundation of China (31070597, 31270656), and the Scientific Research and Graduate Training Joint Programs from BMEC (Stress Resistance Mechanism of Poplar).

Received: 11 January 2013 Accepted: 17 July 2013

Published: 18 July 2013

\section{References}

1. Xie L, Yang Y: Miocene origin of the characteristic broad-leaved evergreen shrub Ammopiptanthus (Leguminosae) in the desert flora of eastern central Asia. Int J Plant Sci 2012, 173(8):944-955.

2. Chen GQ, Crawford D, Huang HW, Ge XJ: Genetic structure and mating system of Ammopiptanthus mongolicus (Leguminosae), an endangered shrub in north-western China. Plant Spec Biol 2009, 24(3):179-188.

3. Rachkovskaya E: Anthropogenic Transformation of Desert Ecosystems in Mongolia. In Sustainable Land Use in Deserts. Edited by Breckle SW, Veste M, Wucherer W. Berlin: Springer; 2001:275-280.

4. Ge XJ, Yu Y, Yuan YM, Huang HW, Yan C: Genetic diversity and geographic differentiation in endangered Ammopiptanthus (Leguminosae) populations in desert regions of northwest China as revealed by ISSR analysis. Ann Bot 2005, 95(5):843-851.

5. Wang W, Chen J, Li J, Zhang Y, Shao Z, Kuai B: Extraordinary accumulations of antioxidants in Ammopiptanthus mongolicus (Leguminosae) and Tetraena mongolica (Zygophyllaceae) distributed in extremely stressful environments. Bot Stud 2007, 48(1):55-61.

6. Xu S, An L, Feng H, Wang X, Li X: The seasonal effects of water stress on Ammopiptanthus mongolicus in a desert environment. J Arid Environ 2002, 51(3):437-447

7. Chen JH, Sun Y, Sun F, Xia XL, Yin WL: Tobacco plants ectopically expressing the Ammopiptanthus mongolicus AmCBL1 gene display enhanced tolerance to multiple abiotic stresses. Plant Growth Regul 2011, 63(3):259-269.

8. Liu RL, Liu MQ, Liu J, Chen YZ, Chen YY, Lu CF: Heterologous expression of a Ammopiptanthus mongolicus late embryogenesis abundant protein gene (AmLEA) enhances Escherichia coli viability under cold and heat stress. Plant Growth Regul 2010, 60(2):163-168,

9. Wei Q, Hu P, Kuai BK: Ectopic expression of an Ammopiptanthus mongolicus $\mathrm{H}^{+}$-pyrophosphatase gene enhances drought and salt tolerance in Arabidopsis. Plant Cell Tiss Org 2012, 110(3):359-369.

10. Wei Q, Guo YJ, Cao HM, Kuai BK: Cloning and characterization of an AtNHX2-like $\mathrm{Na}+/ \mathrm{H}+$ antiporter gene from Ammopiptanthus mongolicus (Leguminosae) and its ectopic expression enhanced drought and salt tolerance in Arabidopsis thaliana. Plant Cell Tiss Org 2011, 105(3):309-316.

11. Liu MQ, Lu CF, Shen X, Yin WL: Characterization and function analysis of a cold-induced AmCIP gene encoding a dehydrin-like protein in Ammopiptanthus mongolicus. DNA Seq 2006, 17(5):342-349.

12. Van Buskirk HA, Thomashow MF: Arabidopsis transcription factors regulating cold acclimation. Physiol Plantarum 2006, 126(1):72-80

13. Cheng C, Yun K-Y, Ressom HW, Mohanty B, Bajic VB, Jia Y, Yun SJ, Reyes BG D I: An early response regulatory cluster induced by low temperature and hydrogen peroxide in seedlings of chillingtolerant japonica rice. BMC Genomics 2007, 8:175

14. Christov NK, Yoneyama S, Shimamoto Y, Imai R: Differential expression of wheat genes during cold acclimation. Cytol Genet 2007, 41(3):142-150.

15. Cao PX, Song J, Zhou CJ, Weng ML, Liu J, Wang FX, Zhao F, Feng DQ, Wang B. Characterization of multiple cold induced genes from Ammopiptanthus mongolicus and functional analyses of gene AmEBP1. Plant Mol Biol 2009, 69(5):529-539.

16. Gilmour SJ, Zarka DG, Stockinger EJ, Salazar MP, Houghton JM, Thomashow MF: Low temperature regulation of the Arabidopsis CBF family of AP2 transcriptional activators as an early step in cold-induced COR gene expression. Plant J 1998, 16(4):433-442

17. Morozova O, Hirst M, Marra MA: Applications of new sequencing technologies for transcriptome Analysis. Annu Rev Genom Hum G 2009, 10:135-151.

18. Wang B, Guo G, Wang C, Lin Y, Wang X, Zhao M, Guo Y, He M, Zhang Y, Pan L: Survey of the transcriptome of Aspergillus oryzae via massively parallel mRNA sequencing. Nucleic Acids Res 2010, 38(15):5075-5087.

19. Zhang G, Guo G, Hu X, Zhang Y, Li Q, Li R, Zhuang R, Lu Z, He Z, Fang X, Chen L, Tian W, Tao Y, Kristiansen K, Zhang X, Li S, Yang H, Wang J, Wang J: Deep RNA sequencing at single base-pair resolution reveals high complexity of the rice transcriptome. Genome Res 2010, 20(5):646-654.

20. Morozova O, Marra MA: Applications of next-generation sequencing technologies in functional genomics. Genomics 2008, 92(5):255-264.

21. Qiu Q, Ma T, Hu Q, Liu B, Wu Y, Zhou H, Wang Q, Wang J, Liu J: Genomescale transcriptome analysis of the desert poplar, Populus euphratica. Tree Physiol 2011, 31(4):452-461.

22. Xu DL, Long H, Liang JJ, Zhang J, Chen X, Li JL, Pan ZF, Deng GB, Yu MQ De novo assembly and characterization of the root transcriptome of Aegilops variabilis during an interaction with the cereal cyst nematode. BMC Genomics 2012, 13:133.

23. Trick M, Long Y, Meng J, Bancroft I: Single nucleotide polymorphism (SNP) discovery in the polyploid Brassica napus using Solexa transcriptome sequencing. Plant Biotechnol J 2009, 7(4):334-346.

24. Li P, Ponnala L, Gandotra N, Wang L, Si Y, Tausta SL, Kebrom TH, Provart N, Patel R, Myers CR, Reidel EJ, Turgeon R, Liu P, Sun Q, Nelson T, Brutnell TP: The developmental dynamics of the maize leaf transcriptome. Nat Genet 2010, 42(12):1060-1067.

25. Zhang J, Liang S, Duan J, Wang J, Chen S, Cheng Z, Zhang Q, Liang X, Li Y: De novo assembly and Characterisation of the Transcriptome during seed development, and generation of genic-SSR markers in Peanut (Arachis hypogaea L.). BMC Genomics 2012, 13:90.

26. Gahlan P, Singh HR, Shankar R, Sharma N, Kumari A, Chawla V, Ahuja PS, Kumar S: De novo sequencing and characterization of Picrorhiza kurrooa transcriptome at two temperatures showed major transcriptome adjustments. BMC Genomics 2012, 13:126.

27. Whitelaw CA, Barbazuk WB, Pertea G, Chan AP, Cheung F, Lee Y, Zheng L, van Heeringen S, Karamycheva S, Bennetzen JL, SanMiguel P, Lakey N, Bedell J, Yuan Y, Budiman MA, Resnick A, Aken SV, Utterback T, Riedmuller S, Williams M, Feldblyum T, Schubert K, Beachy R, Fraser CM, Quackenbush $\mathrm{J}$ : Enrichment of gene-coding sequences in maize by genome filtration. Science 2003, 302(5653):2118-2120.

28. Arumuganathan $\mathrm{K}$, Earle E: Nuclear DNA content of some important plant species. Plant Mol Biol Rep 1991, 9(3):208-218.

29. Grabherr MG, Haas BJ, Yassour M, Levin JZ, Thompson DA, Amit I, Adiconis X, Fan L, Raychowdhury R, Zeng Q, Chen Z, Mauceli E, Hacohen N, Gnirke A, 
Rhind N, Palma FD, Birren BW, Nusbaum C, Lindblad-Toh K, Friedman N, Regev A: Full-length transcriptome assembly from RNA-Seq data without a reference genome. Nat Biotechnol 2011, 29(7):644-652.

30. Thomashow MF: Plant cold acclimation: Freezing tolerance genes and Regulatory mechanisms. Ann Rev Plant Physiol Plant Mol Biol 1999, 50:571-599.

31. Thomashow MF: So what's new in the field of plant cold acclimation? Lots! Plant Physio/ 2001, 125(1):89-93.

32. Chen GQ, Huang HW, Ge XJ: Development and characterization of microsatellite markers for an endangered shrub, Ammopiptanthus mongolicus (Leguminosae) and cross-species amplification in Ammopiptanthus nanus. Conserv Genet 2007, 8(6):1495-1497.

33. Zhou YJ, Gao F, Liu R, Feng JC, Li HJ: De novo sequencing and analysis of root transcriptome using 454 pyrosequencing to discover putative genes associated with drought tolerance in Ammopiptanthus mongolicus. BMC Genomics 2012, 13:226.

34. Xin Z: Cold comfort farm: the acclimation of plants to freezing temperatures. Plant Cell Environ 2001, 23(9):893-902.

35. Seki M, Narusaka M, Abe H, Kasuga M, Yamaguchi-Shinozaki K, Carninci P, Hayashizaki Y, Shinozaki K: Monitoring the expression pattern of 1300 Arabidopsis genes under drought and cold stresses by using a full-length cDNA microarray. Plant Cell 2001, 13(1):61-72

36. Fowler S, Thomashow MF: Arabidopsis transcriptome profiling indicates that multiple regulatory pathways are activated during cold acclimation in addition to the CBF cold response pathway. Plant Cell 2002, 14(8):1675-1690.

37. Kawamura $Y$, Uemura M: Mass spectrometric approach for identifying putative plasma membrane proteins of Arabidopsis leaves associated with cold acclimation. Plant J 2003, 36(2):141-154.

38. Moellering ER, Muthan B, Benning C: Freezing tolerance in plants requires lipid remodeling at the outer chloroplast membrane. Science 2010, 330(6001):226-228.

39. Degenkolbe T, Giavalisco P, Zuther E, Seiwert B, Hincha DK, Willmitzer L Differential remodeling of the lipidome during cold acclimation in natural accessions of Arabidopsis thaliana. Plant J 2012, 32(6):972-982.

40. Gibson S, Arondel V, Iba K, Somerville C: Cloning of a temperatureregulated gene encoding a chloroplast omega-3 desaturase from Arabidopsis thaliana. Plant Physiol 1994, 106(4):1615-1621.

41. Ashraf M, Foolad MR: Roles of glycine betaine and proline in improving plant abiotic stress resistance. Environ Exp Bot 2007, 59(2):206-216

42. Szekely G, Abraham E, Cseplo A, Rigo G, Zsigmond L, Csiszar J, Ayaydin F, Strizhov N, Jasik J, Schmelzer E, et al: Duplicated P5CS genes of Arabidopsis play distinct roles in stress regulation and developmental control of proline biosynthesis. Plant J 2008, 53(1):11-28.

43. Verbruggen $\mathrm{N}$, Hermans C: Proline accumulation in plants: a review. Amino Acids 2008, 35(4):753-759.

44. Strand A, Foyer CH, Gustafsson P, Gardestrom P, Hurry V: Altering flux through the sucrose biosynthesis pathway in transgenic Arabidopsis thaliana modifies photosynthetic acclimation at low temperatures and the development of freezing tolerance. Plant Cell Environ 2003, 26(4):523-535.

45. Tunnacliffe A, Wise MJ: The continuing conundrum of the LEA proteins. Naturwissenschaften 2007, 94(10):791-812.

46. Rajesh S, Manickam A: Prediction of functions for two LEA proteins from mung bean. Bioinformation 2006, 1(4):133-138

47. Suzuki N, Mittler R: Reactive oxygen species and temperature stresses: a delicate balance between signaling and destruction. Physiol Plantarum 2006, 126(1):45-51.

48. Baek KH, Skinner DZ: Alteration of antioxidant enzyme gene expression during cold acclimation of near-isogenic wheat lines. Plant Sci 2003, 165(6):1221-1227.

49. Shi J, Liu M, Shi J, Zheng G, Wang Y, Wang J, Chen Y, Lu C, Yin W: Reference gene selection for qPCR in Ammopiptanthus mongolicus under abiotic stresses and expression analysis of seven ROS-scavenging enzyme genes. Plant Cell Rep 2012, 31(7):1245-1254.

50. Kuk YI, Shin JS, Burgos NR, Hwang TE, Han O, Cho BH, Jung SY, Guh JO: Antioxidative enzymes offer protection from chilling damage in rice plants. Crop Sci 2003, 43(6):2109-2117.

51. Saijo $Y$, Hata S, Kyozuka J, Shimamoto K, Izui K: Over-expression of a single $\mathrm{Ca}^{2+}$-dependent protein kinase confers both cold and salt/drought tolerance on rice plants. Plant J 2000, 23(3):319-327.
52. Ludwig AA, Romeis T, Jones JDG: CDPK-mediated signalling pathways: specificity and cross-talk. J Exp Bot 2004, 55(395):181-188.

53. Gusta LV, Trischuk R, Weiser CJ: Plant cold acclimation: The role of abscisic acid. J Plant Growth Regul 2005, 24(4):308-318.

54. Agarwal PK, Jha B: Transcription factors in plants and ABA dependent and independent abiotic stress signalling. Biol Plantarum 2010, 54(2):201-212

55. Ma Y, Szostkiewicz I, Korte A, Moes D, Yang Y, Christmann A, Grill E: Regulators of PP2C phosphatase activity function as abscisic acid sensors. Science 2009, 324(5930):1064-1068

56. Yoshida R, Hobo T, Ichimura K, Mizoguchi T, Takahashi F, Aronso J, Ecker JR, Shinozaki K: ABA-activated SnRK2 protein kinase is required for dehydration stress signaling in Arabidopsis. Plant Cell Physiol 2002, 43(12):1473-1483.

57. Kobayashi Y, Murata M, Minami H, Yamamoto S, Kagaya Y, Hobo T, Yamamoto A Hattori T: Abscisic acid-activated SNRK2 protein kinases function in the generegulation pathway of $A B A$ signal transduction by phosphorylating $A B A$ response element-binding factors. Plant J 2005, 44(6):939-949.

58. Uraji M, Katagiri T, Okuma E, Ye W, Hossain MA, Masuda C, Miura A, Nakamura Y, Mori IC, Shinozaki K, Murata Y: Cooperative function of PLD delta and PLD alpha 1 in abscisic acid-induced stomatal closure in Arabidopsis. Plant Physiol 2012, 159(1):450-460.

59. Testerink C, Munnik T: Phosphatidic acid: a multifunctional stress signaling lipid in plants. Trends Plant Sci 2005, 10(8):368-375.

60. Singh K, Foley RC, Onate-Sanchez L: Transcription factors in plant defense and stress responses. Curr Opin Plant Biol 2002, 5(5):430-436.

61. Galbraith DW, Harkins KR, Maddox JM, Ayres NM, Sharma DP, Firoozabady E: Rapid flow cytometric analysis of the cell cycle in intact plant tissues. Science 1983, 220(4601):1049-1051.

62. Chang S, Puryear J, Cairney J: A simple and efficient method for isolating RNA from pine trees. Plant Mol Biol Rep 1993, 11(2):113-116.

63. Pertea $G$, Huang $X Q$, Liang F, Antonescu V, Sultana R, Karamycheva S, Lee $Y$, White J, Cheung F, Parvizi B, Tsai J, Quackenbush J: TIGR Gene Indices clustering tools (TGICL): a software system for fast clustering of large EST datasets. Bioinformatics 2003, 19(5):651-652.

64. Conesa A, Gotz S, Garcia-Gomez JM, Terol J, Talon M, Robles M: Blast2GO: a universal tool for annotation, visualization and analysis in functional genomics research. Bioinformatics 2005, 21(18):3674-3676.

65. Ye J, Fang L, Zheng H, Zhang Y, Chen J, Zhang Z, Wang J, Li S, Li R, Bolund L, Wang J: WEGO: a web tool for plotting GO annotations. Nucleic Acids Res 2006, 34:W293-W297.

66. Kanehisa M, Araki M, Goto S, Hattori M, Hirakawa M, Itoh M, Katayama T, Kawashima S, Okuda S, Tokimatsu T, et al: KEGG for linking genomes to life and the environment. Nucleic Acids Res 2008, 36:D480-D484.

67. Iseli C, Jongeneel CV, Bucher P: ESTScan: a program for detecting, evaluating, and reconstructing potential coding regions in EST sequences. Proc Int Confn Intell Syst Mol Biol 1999, 7:138-148.

68. Mortazavi A, Williams BA, McCue K, Schaeffer L, Wold B: Mapping and quantifying mammalian transcriptomes by RNA-Seq. Nat Methods 2008, 5(7):621-628.

69. Audic S, Claverie JM: The significance of digital gene expression profiles. Genome Res 1997, 7(10):986-995.

70. Reiner A, Yekutieli D, Benjamini Y: Identifying differentially expressed genes using false discovery rate controlling procedures. Bioinformatics 2003, 19(3):368-375.

71. Wu J, Zhang Y, Zhang H, Huang H, Folta KM, Lu J: Whole genome wide expression profiles of Vitis amurensis grape responding to downy mildew by using Solexa sequencing technology. BMC Plant Biol 2010, 10:234.

72. da Hao C, Ge G, Xiao P, Zhang Y, Yang L: The first insight into the tissue specific taxus transcriptome via Illumina second generation sequencing. PLoS One 2011, 6(6):e21220.

73. Livak KJ, Schmittgen TD: Analysis of relative gene expression data using real-time quantitative PCR and the 2(-Delta Delta $C(T))$ Method. Methods 2001, 25(4):402-408

\section{doi:10.1186/1471-2164-14-488}

Cite this article as: Pang et al:: De novo sequencing and transcriptome analysis of the desert shrub, Ammopiptanthus mongolicus, during cold acclimation using Illumina/Solexa. BMC Genomics 2013 14:488. 